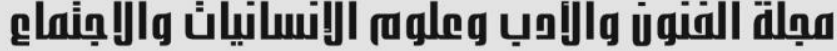

Journal of Arts, Literature, Humanities and Social Sciences www.jalhss.com

\section{الفساد الاجتماعي والاقتصادي في منظور القرآن والسنة}

د. أيمان ياسين حسن

قسم علوم القران ـ كلية التربية ـ الجامعة المستنصرية ـ العراق البريد الاكتروني : d.emanyaseen@gmail.com

المستخلص

هدف هذا البحث بشكل أساسي الى التعرف على مفهوم الفساد ومكافحته ووقاية منه من منظور الفكر الإسلامي و السنة النبوية و ويتضح من خلال ذلك أن الدين الإسلامي قد شخص داء الفساد ووصف الدو اء لمكافحته و الوقاية منه، وجاء بقو اعد وأحكام هدفت إلى الحد من هذه الظاهرة ما أمكن، واعتبرت أن كل فعل أو امتتاع من شأنه أن

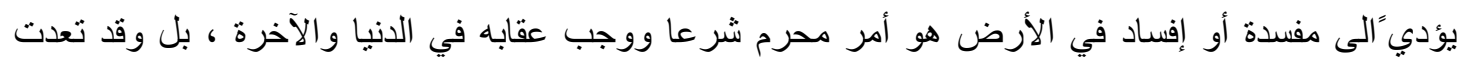
الثريعة الإسلامية ذلك باعتبار ها أن مكافحة الفساد فريضة قائمة إلى يوم القيامة أوجبها الله تعالى على الناس. إن الناظر لا تخطئ عينيه صور الخلل ، و المفارقات الكبيرة ، والمباينات الثاسعة بين و اقع الأمة ومنهج الإسلام ـ فالناظر يرى صور الانحراف كثيرة وعميقة ، و متعددة الأمثلة وبيّنة فيما تبديه من ممارسات ظاهرة أو

$$
\text { مستترة ، حتى إن الإنسان إذا أمعن في جمع هذه المتفرقات. }
$$

إن الحديث عن الفساد لا يخص مجتمعا بعينه أو دولة بذاتها ، و إنما هو ظاهرة عالمية تشكو منها كل الدول . وتم التوصل من خلال هذا البحث إلى جملة من التوصيات، أهمها ضرورة الاهتمام بتنمية الوعي الديني لدى عموم المواطنين للحث على النزاهة ومحاربة الفساد عبر وسائل الإعلام المختلفة، وخطباء المساجد و العلماء

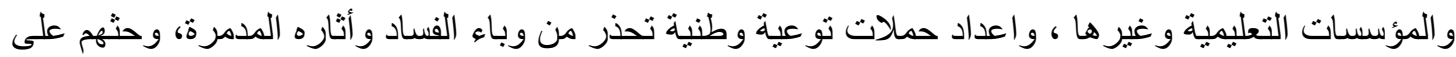
التعاون مع الجهات المعنية بمكافحة الفساد، و الإبلاغ عن جر ائم الفساد ومرتكبيها، وتوجيه علماء وطلبة الإدارة و الباحثين ممن لديهم سعة إطلاع في العلوم الثرعية إلى إجراء مزيد من البحوث والدراسات التي تنين دور الثريعة الإسلامية في الحد من هذه الآفة الخطيرة وتجنب آثار ها المدمرة. 


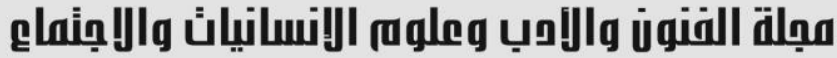 \\ Journal of Arts, Literature, Humanities and Social Sciences www.jalhss.com \\ Volume (58) September 2020 \\ العدد (58) سبتمبر 2020 - | (20)
}

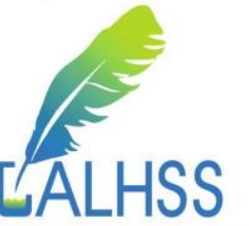

\section{Social and Economic Corruption in the Perspective of the Qur'an and Sunnah}

\author{
Dr. Iman Yassin Hassan \\ Department of Quranic Sciences - College of Education \\ Al-Mustansiriya University - Iraq \\ Email: d.emanyaseen@gmail.com
}

\begin{abstract}
The aim of this research is mainly to identify the concept of corruption and its fight and prevention from the perspective of Islamic thought and the prophetic Sunnah. It is clear from this that the Islamic religion has diagnosed the disease of corruption and described the medicine to combat and prevent it, and came with rules and provisions aimed at reducing this phenomenon as possible, and considered That any act or omission that would lead to corruption or corruption on earth is prohibited by law and punishable in this world and the hereafter, and Islamic Sharia has gone beyond that as fighting corruption is an obligation until the Day of Resurrection that God Almighty has required of people.

The beholder does not mistake the images of imbalances, large paradoxes, and the vast differences between the reality of the nation and the approach of Islam. The viewer sees the images of deviation many, deep, and multiple examples and shown in the manifestations of the practices appearing or hidden, so that if a person dwells in the collection of these miscellaneous.

Talking about corruption does not concern a particular society or a country in itself, but rather is a global phenomenon that all countries complain of.

Through this research, a set of recommendations were reached, the most important of which is the need to pay attention to developing religious faith among all citizens to urge integrity and fight corruption through various media outlets, mosque preachers, scholars, educational institutions and others, and prepare national awareness campaigns warning of the epidemic of corruption and its destructive effects, and urge them to adopt Cooperating with the authorities concerned with combating corruption, reporting corruption crimes and their perpetrators, and directing scholars, administration students, and researchers who are well-informed in Sharia sciences to conduct more research and studies that demonstrate the role of Islamic law in reducing this dangerous scourge and avoiding its destructive effects.
\end{abstract}

Keywords: Quran, Sunnah, society, corruption, economics. 


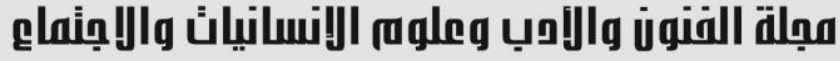

Journal of Arts, Literature, Humanities and Social Sciences www.jalhss.com

الفساد قديم قدم الإنسان نفسه، فمنذ أن خلق الله عز وجل الأرض عرف الفساد بأنواعه وأساليبه المختلفة ـ هدفه

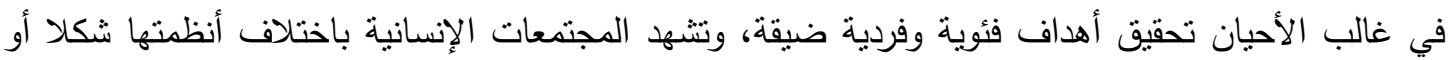
اشكال أخرى من أثكال الفساد، فالفساد كغيره من مفاهيم الخير والثر كل منهما مرتبط بالنفس البشرية والطبيعة الإنسانية منذ مهذ الخليقة، والفساد يغذى نفسه بنفسه ويخلق مناخا واسعا من الأعمال غير المشروعة التي هني تقوض عمليات التتمية، فهو يعد آفة المجتمعات وهو ليس بظاهرة غير مرغوب بها فحسب، بل ظاهرة خطبرة

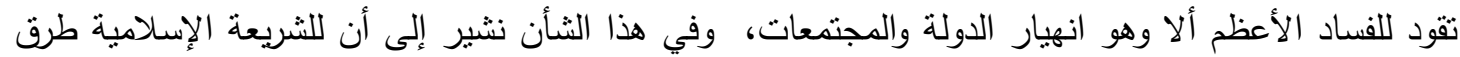

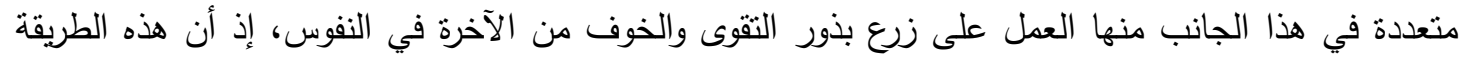

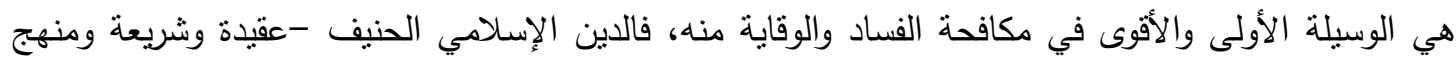
حياة- هو الركيزة الأساسية التي تحكم منطلقات وأهداف ووسائل وآليات الوقاية من الفساد ومكافحته ، وتعد كل الإنل عمل من شأنه الانحراف بالوظيفة العامة والخاصة عن مسارها الشرعي والنظامي الذي وجدت لخدمته فسادا .

$$
\text { وجريمة تستوجب العقاب في الدنبا والآخر . }
$$

وتضمن البحث ثلاث مباحث تتاول المبحث الأول مفهوم الفساد لغة واصطلاحا ، وتتاول المبحث الثاني مفهوم

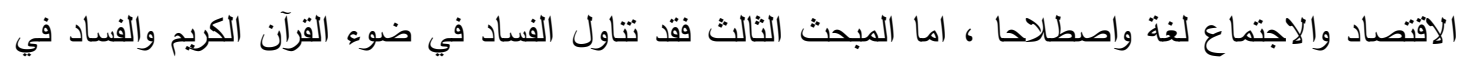

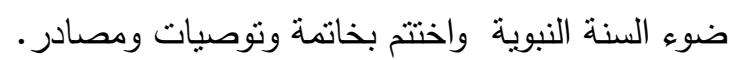

\section{The concept of corruption اولا : مفهوم الفساد}

تستخدم كلمة "الفساد" للتعبير عن مجموعة من السلوكيات غير الصحيحة كالرشوة والاختلاس وإساءة استخدام السلطة والابتزاز والإثراء غير المشروع والأتاوات والمتاجرة بالنفوذ، بالاضافة الى افعال ترنبط بأنشطة الفساد

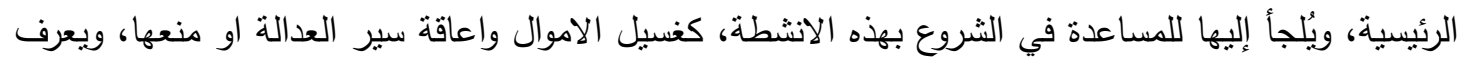

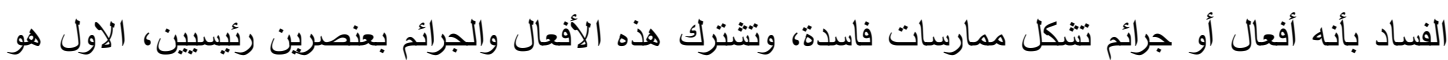

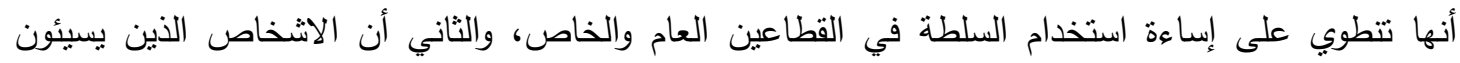

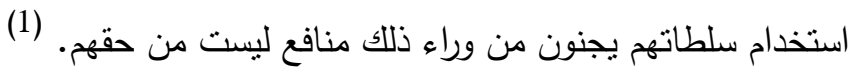
ثانيا : الفساد لغة واصطلاحا الفساد لغة: : Corruption Language ان الفساد في معاجم اللغة من ( فسد ) ضد صلح والفساد لغة البطلان ، فيقال فسد الثيء أي بطل

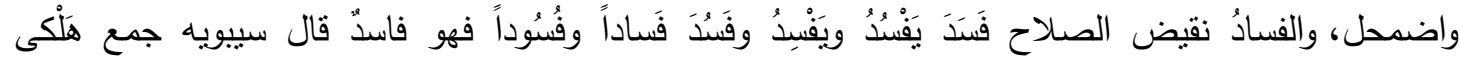
لتقاربهما في المعنى وأَفَسَدَه

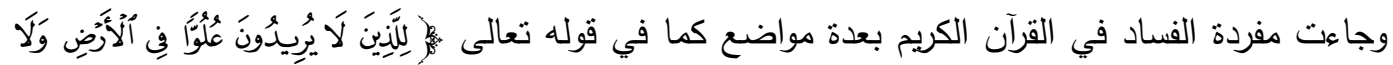

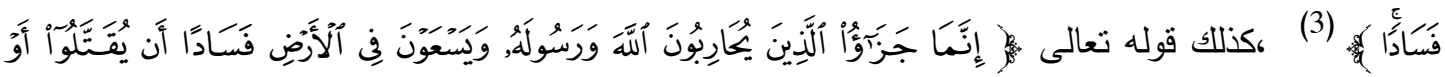




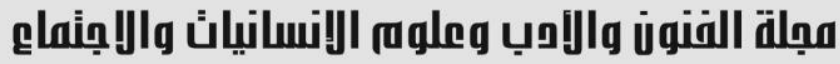

Journal of Arts, Literature, Humanities and Social Sciences www.jalhss.com

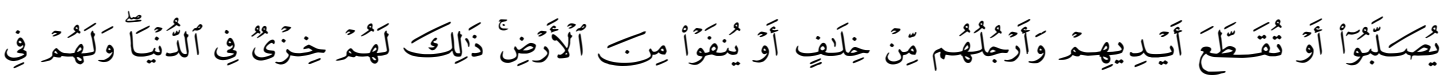

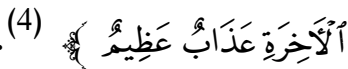

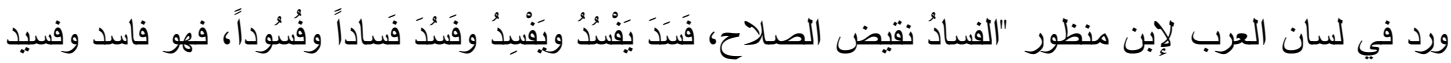
فيهما. وقوم فسدى. وأفسده هو واستفسد فلان إلى فلان. وتفاسد القوم: تدابروا وقطعوا الأرحام؛ واستفسد السلطان

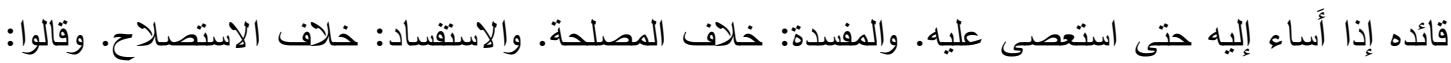

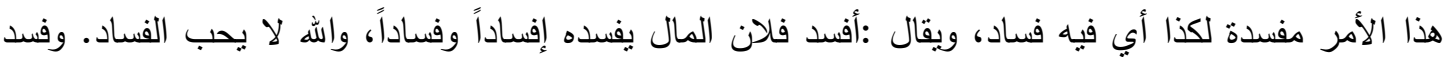
النشيءً إذا أباره.

Corruption idiomatically الفساد اصطلاحا وفي الاصطلاح، فالفساد هو "خروج الثيء عن الاعتدال، قليلا كان الخروج عنه أو كثثرا، أو هو العدول عن

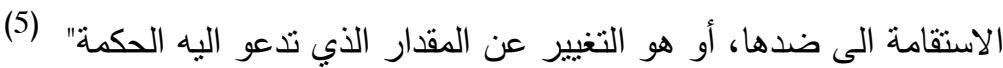

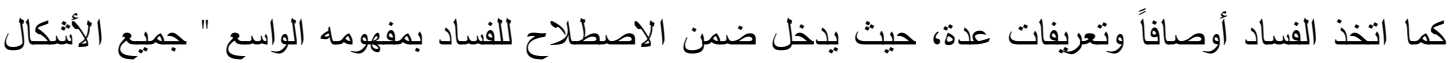
والعمليات الفسادية، سواء كان ذلك سوء استخدام السلطة واستغلال النفوذ، او الوضع الخاص الذي يحتله شخص ما في الحياة العامة، أو جميع أنواع الرشوة المكثوفة والمستترة والنقدية والعينية، سواء فيما يتعلق بإتمام الصفقات والمعاملات بين الافراد والدولة، أو داخل تلون

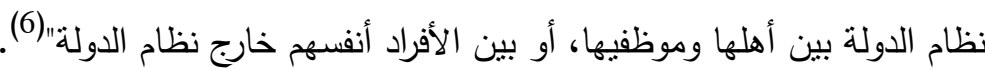

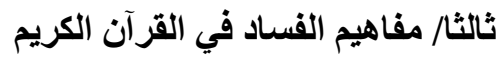
وردت عبارة (الفساد) وتعريفاتها في خمسين آية ، كما وردت امثال ذلك العدد من الآيات تتتاول مفاهيم الفساد المختلفة ، كالغش والتبذير والاسراف والربا والاكتتاز ، وأكل السحت... وغيرها من المفاهيم التي نسبب اثارا" سيئة على المجتمع وسلوكه وموارده ، وكل نلك الآيات تتيذ الفساد وتحذر منه وتعتبره مدعاة لغضب الله

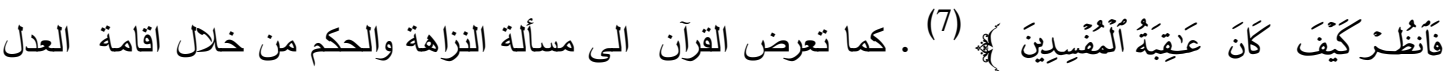

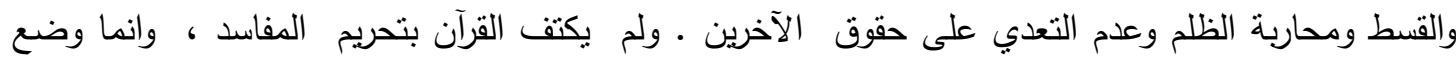
حلولا" لكيفية تجنبها من خلال تربية النفس باتجاه المتل العليا والسعي للحصول على مرضاة اله تعالى . وهكذا نجد ان التعاريف لمفهوم الفساد نتعدد وتختلف ، ولعل ذلك الاختلاف راجع لسببين: الاول : عدم اتفاق الباحثين على أي نوع من انواع السلوك الذي ينبغي ادراجه أو إسنبعاده من مفهوم الفساد. الثاني : اختلاف التقافة من بلد لآخر ، وكذا القوانين والاعراف الاجتماعية التي تجيز سلوكيات معينة فاسدة في نظر بلدان اخرى - مبل 


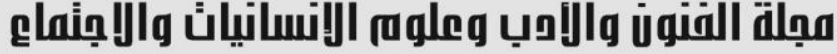

Journal of Arts, Literature, Humanities and Social Sciences www.jalhss.com

إن مفهوم الاقتصاد لغةً هو: القَصدَ: الوسط بين الطرفين، والقَصدُ: إتيان الثيء، والقَصد: في الثيء خلاف

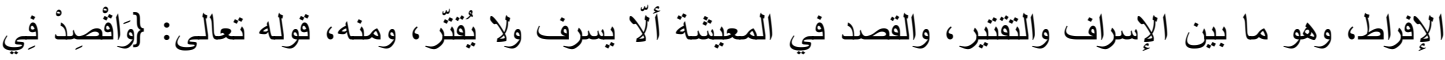

أما مفهوم الاقتصاد اصطلاحًا فهو: "دراسة سلوك الإنسان في إدارة الموارد النادرة وتتميتها لإثباع حاجاته" (9)، وقد عرف شيخ الإسلام العز بن عبد السلام -رحمه الهـ- الاقتصاد بقوله: "الاقتصاد رتبة بين رتبتين ومنزلة بين منزلتين، والمنازل ثلاث: التقصير في جلب المصالح، والإسراف في جلبها، والاقتصاد بينهما". (10) ويتغير مفهوم الاقتصاد من زمن إلى آخر ، فقد ابتدأ مفهوم الاقتصاد عند الإغريق، حين كان يقتصر على مسؤولية أفراد

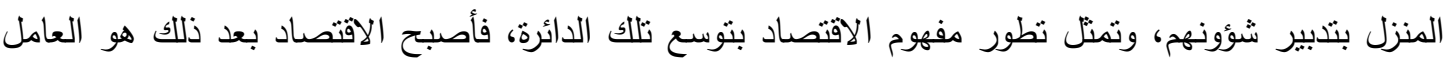
الأول في سيرورة عمل أب شركة، وبعد ذلك، أصبح الاقتصاد هو المتحكم الأول في العلاقات الدولية، وأصبح

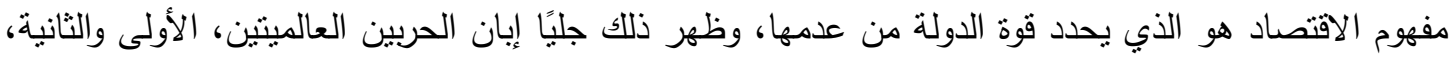

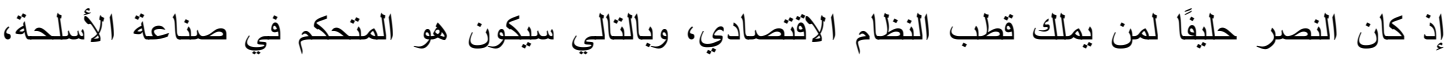
والتي هي بدورها ستبين موقف الخاسر من المنتصر .

وقد تعددت وتتباينت أنثكال وأنماط الفساد الاقتصادي من مجتمع لآخر ، فنها ما هو محرم شرعاً في الدين مثل هاتل

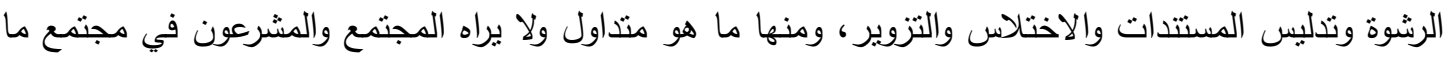

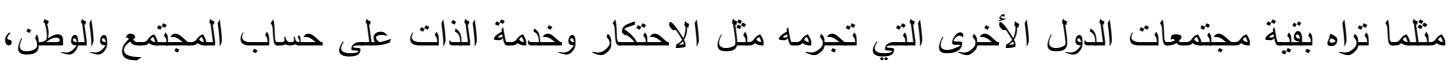
ناهيك عن انعدام المصداقية والثفافية وتضارب المصالح في إدارة مسئول لشئون مؤسستين متضاربنتين في الأهداف والمصالح، بحيث بستغل إحداهما أو كلاهما لتحقيق مصالح شخصية على حساب بقية المستفيدين

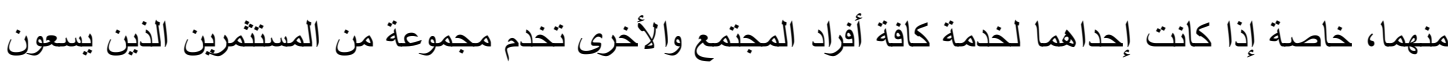
لتعظيم أرباحهم وفوائدهم على حساب بقية أفراد المجتمع والوطن. للاحتكار الاقتصادي أضرار كثيرة على فئى

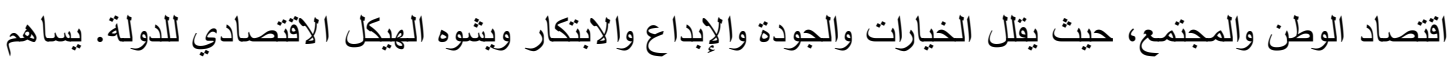
الاحتكار في ارتفاع تكاليف المعيشة والخدمات بشكل عام، بحيث بصبح تضخم الأسعار هاجس الحكومة والمواطن.

مفهوم المجتمع لغة واصطلاحا المجتمع في اللغة هو مصطلح مشتق من الفعل جَمَع، وهي عكس كلمة فرق، كما أنّها مُشتقِّة على وزن مُفنَّكل،

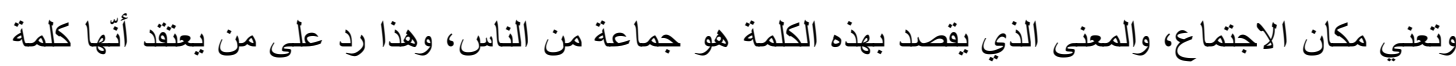




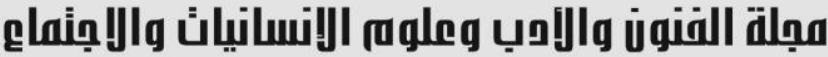

unalla giall thas

Journal of Arts, Literature, Humanities and Social Sciences www.jalhss.com

خاطئة ويقول إنّه ينبغي استخدام كلمة جماعة بدلاً منها، ويُستّى العلم الذي يُعنى بدراسة المجتمع من جميع نواحيه بعلم الاجنماع، (12) والمجتمع لغة كما جاء في معجم المعاني الجامع هو عبارة عن فئة من الناس تشكّل مجموعة تعتمد على لـى بعضها البعض، يعيشون مع بعضهم، وتربطهم روابط ومصالح مشتركة وتحكمهم عادات وتقاليد وقوانين واحدة. (13) وهناك عدة تعريفات للمجتمع من المنظور السياسيّ، والمنظور الاجتماعيّ، والمنظور النفسيّ وغيرها. ويمكن تعريف المجتمع اصطلاحاً على أنّه عدد كبير من الأفراد المستقرّين الذين تجمعهم روابط اجتماعية

ومصالح مشتركة ترافقها أنظمة تهدف إلى ضبط سلوكه ويكونون تحت رعاية السلطة، (14) الفساد المجمعي يمكن أن يوجد الفساد في البلدان الغنية والفقيرة على حد سواء، ولكنّه يختلف من ناحية طبيعته

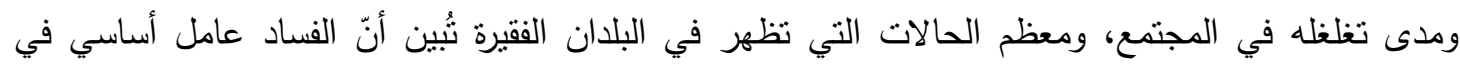
الكثير من المجالات؛ كنقص المياه في معظم الميادين، وقطع أثنار الغابات بشكل غير فئن فانوني، وعدم العدل

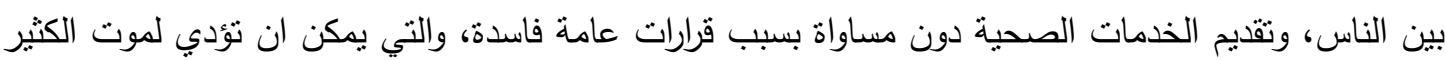
من الأشخاص، وتجاهل فرص تعليم الأفراد، وبناء طرق سيئة الجودة، وحدوث المجاعات. (15) ومن مظاهر الفساد في المجتمع 1. الرشوة تعد الرشوة أحد أكثر مظاهر الفساد انتشاراً في القطاع العام، وهي دفع طرف ثالث لوكيل الدولة مبلغ من المال من أجل أن يقوم بعمل ما يتعارض مع واجبه. 2. التزوير يُعرف التزوير على أنّه تحريف متعمد يجبر الآخرين على تحمل تكاليف أمور لم يفعلوها وعادة

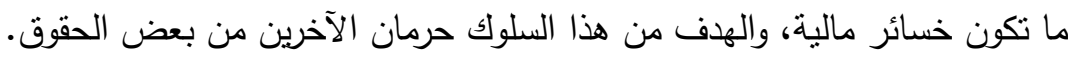

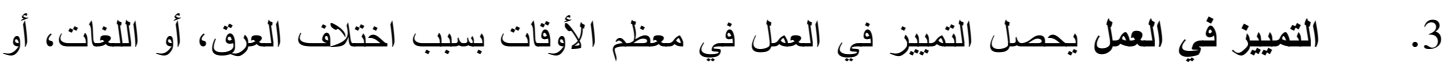
الأصول، والتمييز يعد سلوكاً غير قانوني يحدث عند معاملة شخص ما أو مجموعة من الأشخاص بطريقة أقل تفضيلاً عن غيرهم بسبب عرقه، أو لونه، أو أصله القومي، أو جنسه، أو حالته الاجتماعية، أو عمره، أو دينه. 


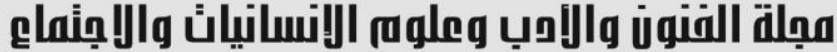

Journal of Arts, Literature, Humanities and Social Sciences www.jalhss.com

\author{
| - المبحث الثالث \\ الفساد في ضوء القران الكريم
}

مفهوم الفساد وأنواعه ومدلولاته في ضوء القرآن الكريم : من المؤكد أن لفظة الفساد في الثريعة الإسلامية نستمد معانيها من القران الكريم الذي نتاولها في آيات كثيرة،

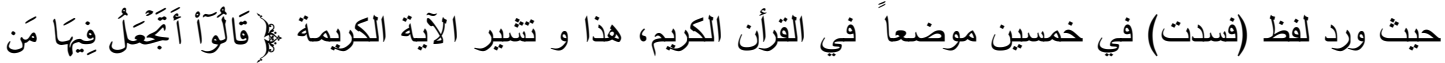

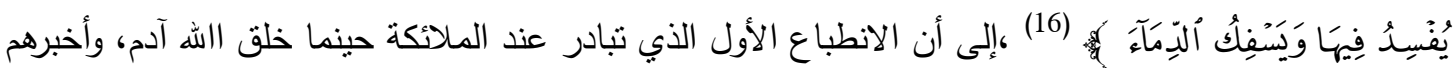
أنه جاعل في الأرض خليفةً كان استقسارا عن إنشاء هذا المخلوق الجديد، ومعنى ذللك بأن الأرض كانت

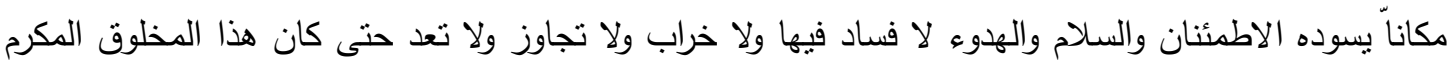
عند الله هو مبدأ الفساد وسفلك الدماء ، وكان الرد الرباني على هذا الاستفسار من الملائكة:

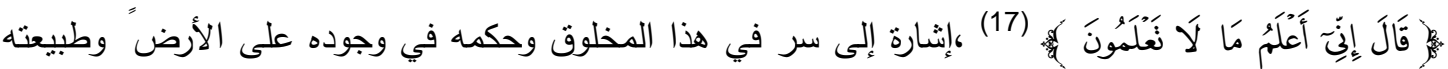

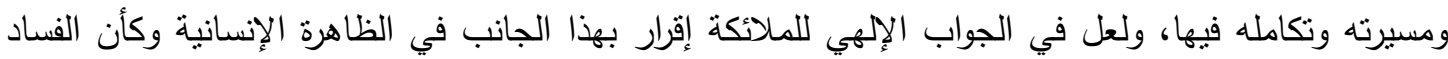
وسفك الدماء ملازمان لطبيعة الإنسان بما بملكه من قدرة على الاختبار والإرادة والتجاوز ، لقوله تعالى: إلنَّا

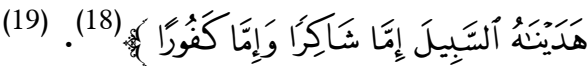
مدلول مصطلح (الفساد) في نصوص القرآن الكريم : سبق وأن تمت الإثـارة إلى أن لفظ (فسدت) وردت في خمسين موضعا في القرآن الكريم، وجميعها لها مدلولات

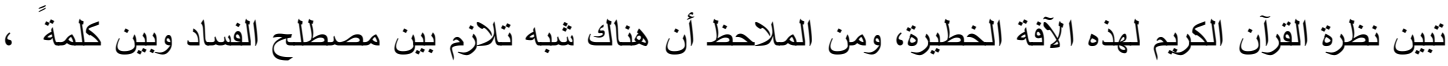
الأرض، وقد ورد هذا التلازم في نحو أربعين آية، وهي بلغة الحساب ثمانين بالمائة تقريبا من مجموع الآيات ،

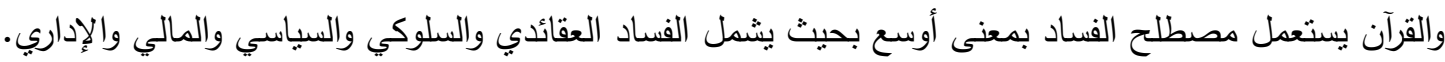

ويأني التعبير على كلمة (فساد) بمعان عدة بحسب موقعه في القرآن الكريم، فهو (الجدب أو القحط) كما في

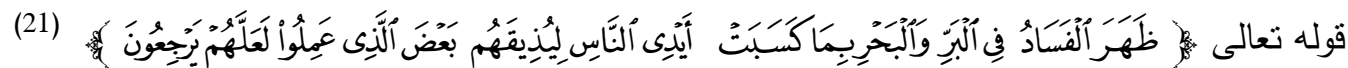

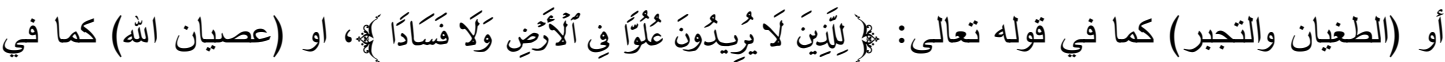

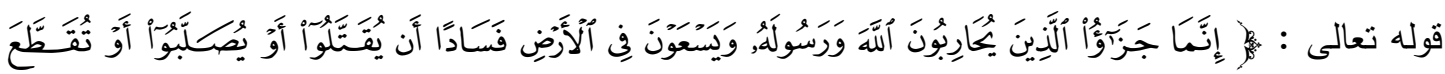

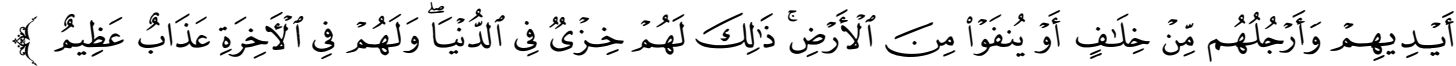
المائدة: بr ويتضح في الآية الكريمة السابقة نتديد القرآن الكريم على تحريم الفساد على نحو كلي، و و أن لمرتكبيه الخزي في الحياة الدنيا والعذاب الثديد في الآخرة. (22) وجاء مصطلح الفساد في القرآن كمقابل لمصطلح الصلاح منل قوله تعالى:

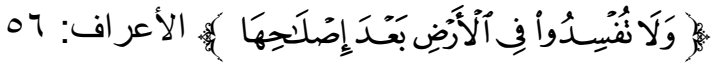




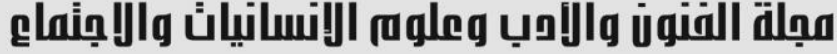

Journal of Arts, Literature, Humanities and Social Sciences www.jalhss.com

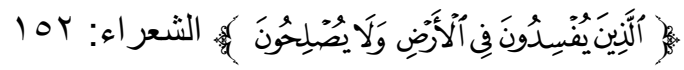

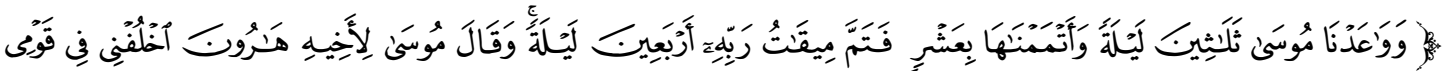

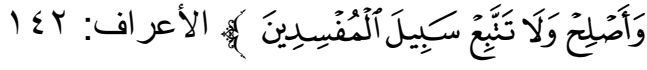

ويتضح مما سبق أن مدلول الفساد في ألفاظ القرآن الكريم جاء ليشمل جميع أنواع الفساد وصوره ولم يقتصر

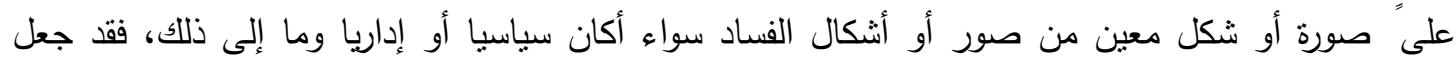
الثرعً الحنيف كل المعاصي فسادا في الأرض، فكل المخالفات خروج عن جادة الصلاح، وانحراف عن الطريق

المستقير.

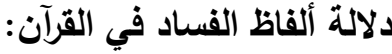

المتتبع لألفاظ القران يجد أن لفظي الفساد والإفساد استعملا للالالة على المعنى العام لهما، كما استعملا للالالة

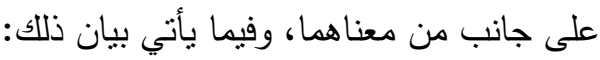

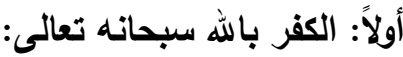

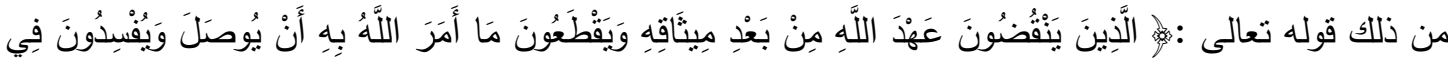

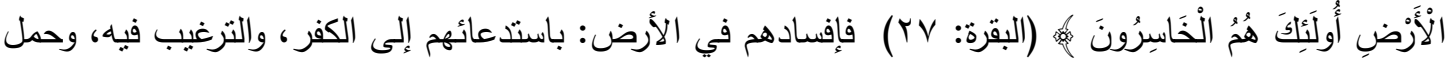

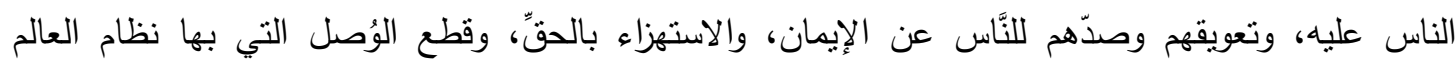

$$
\text { وصلاحه (23) }
$$

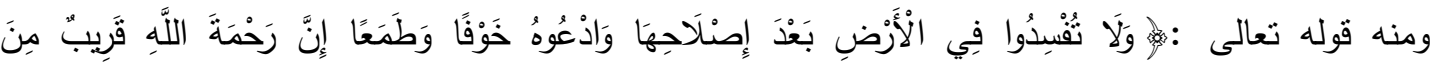

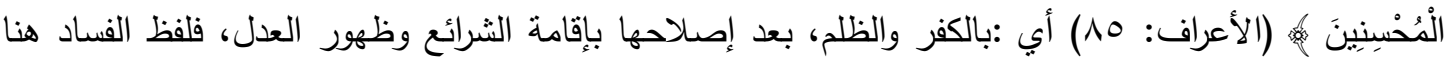

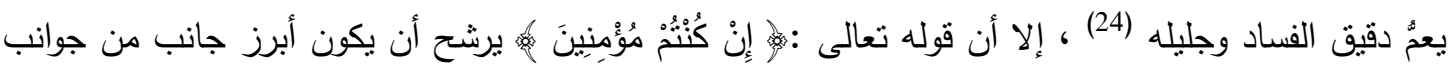
فسادهم هو الكفر بالله سبحانه وتعالى.

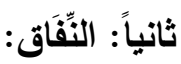

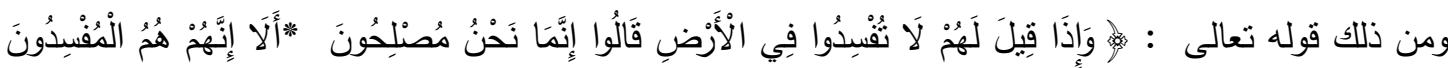

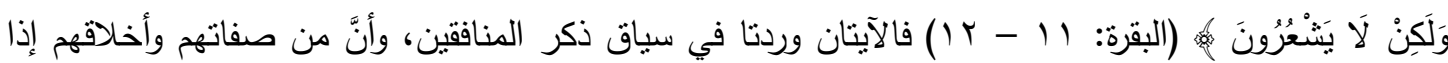

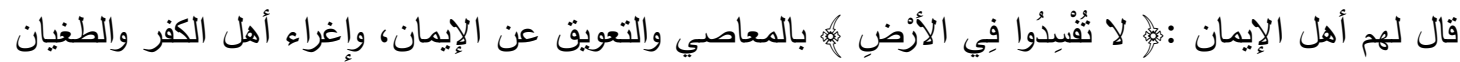

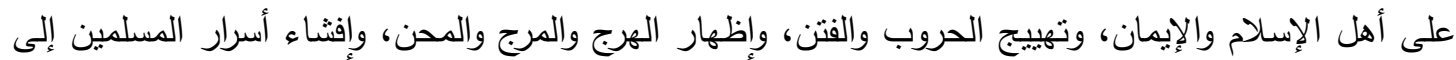

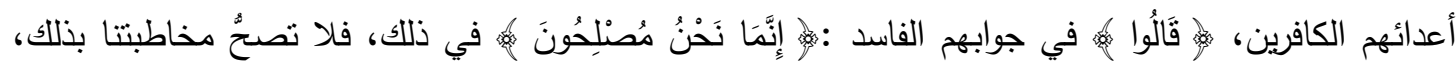

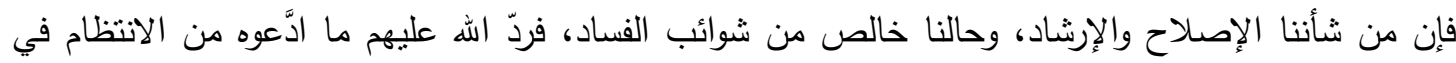

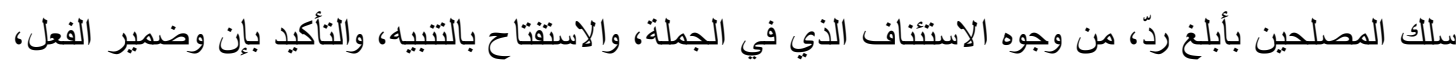
وتعريف الخبر ، والتعبير بنفي الشعور ، إذ لو شعروا أدنى شعور لتحقَّقوا أنهم مفسدون (25). 


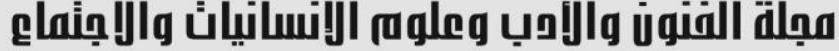

Journal of Arts, Literature, Humanities and Social Sciences www.jalhss.com

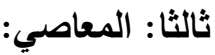

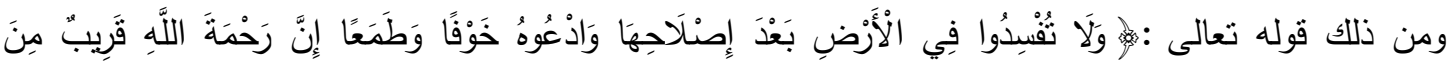

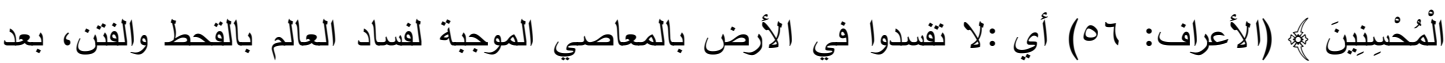

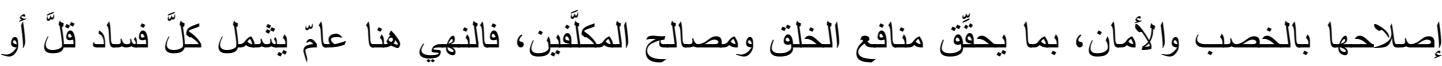

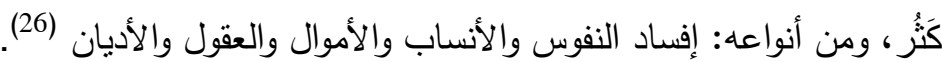

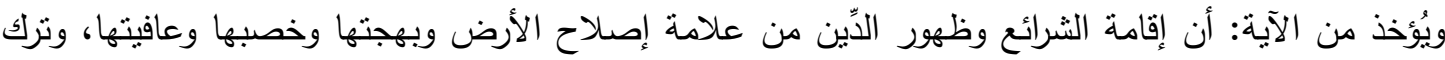
الثرائع وظهور المعاصي من علامة فساد الأرض وخرابها (27). رايعا: خراب العالم وفساد نظامه:

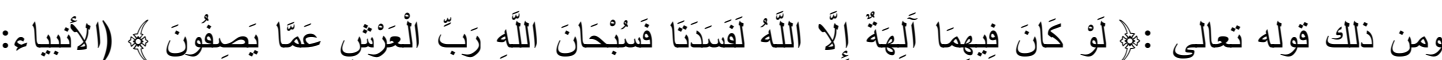

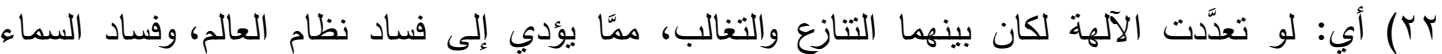
والأرض: هو خرابهما وهلاك من فيهما، وذلك بسبب وقوع التتازع بالاختلاف الواقع بين الثركاء، فيبغي بعضُهح

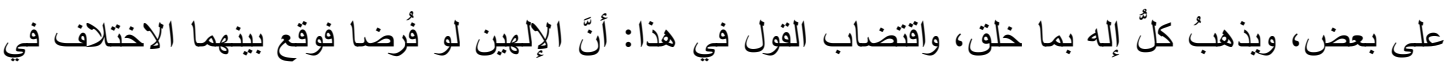

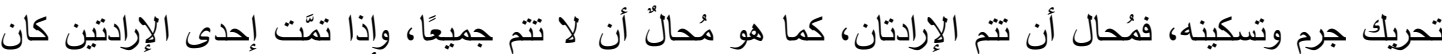

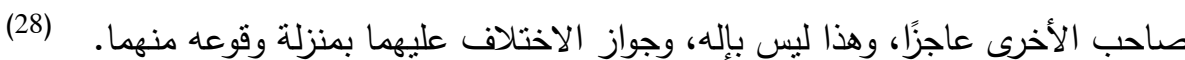

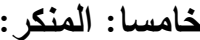

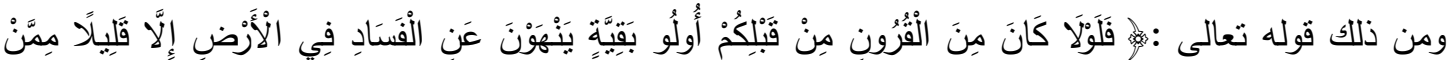

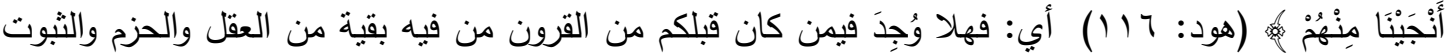

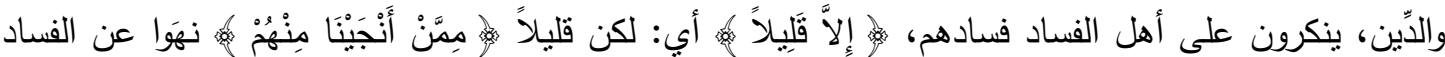
في الأرض. (29)

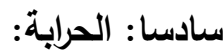

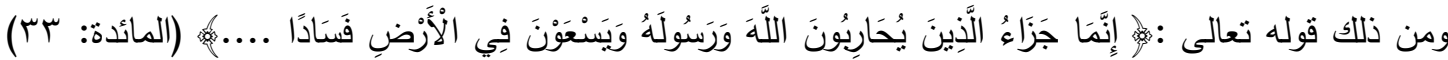

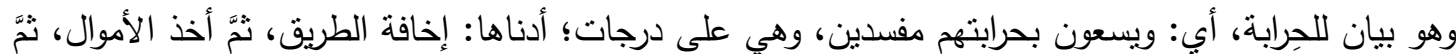
قانل الأنفس. (30)

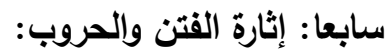

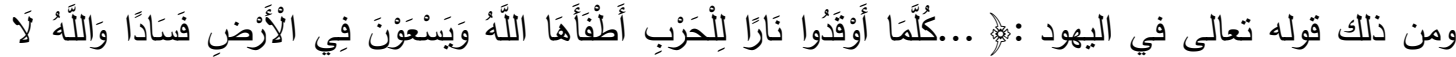

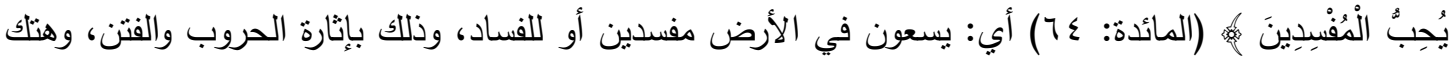

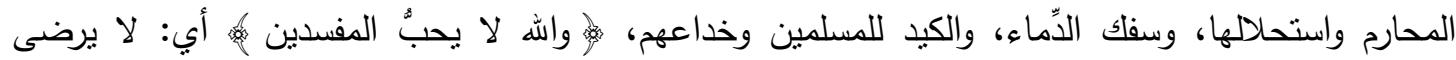

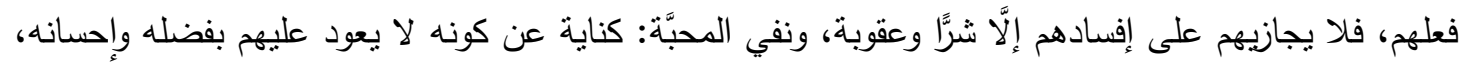

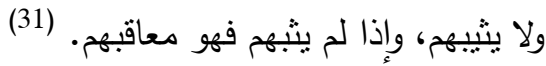




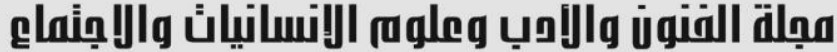

Journal of Arts, Literature, Humanities and Social Sciences www.jalhss.com

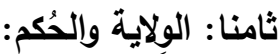

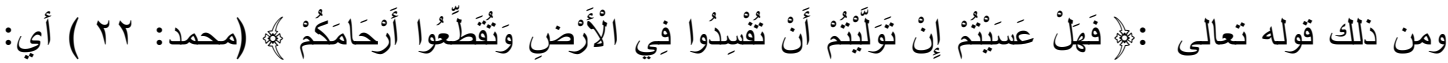

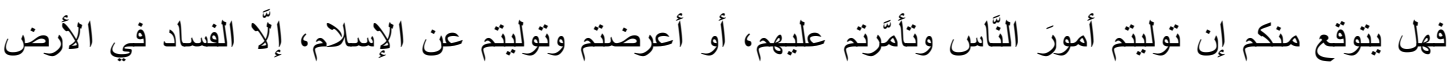

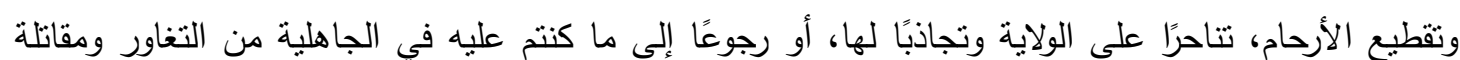

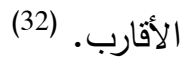

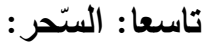

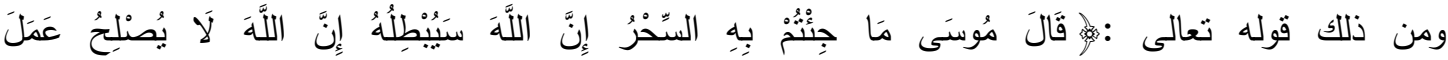

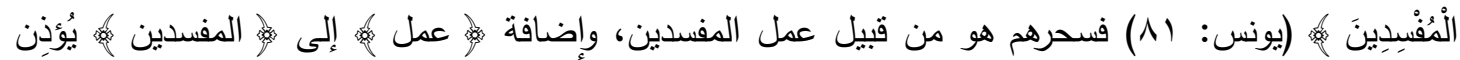

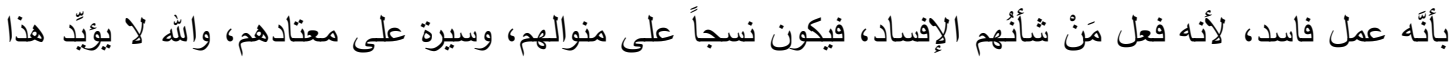

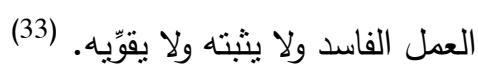

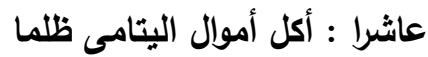

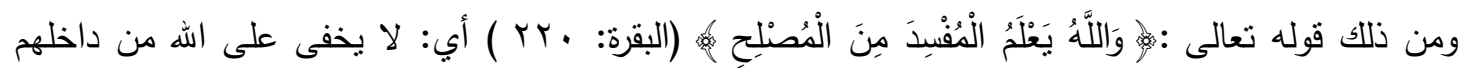

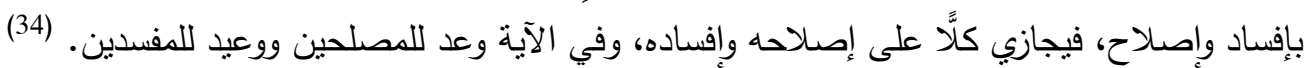

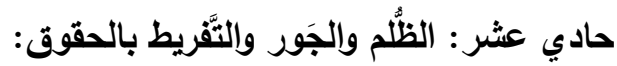

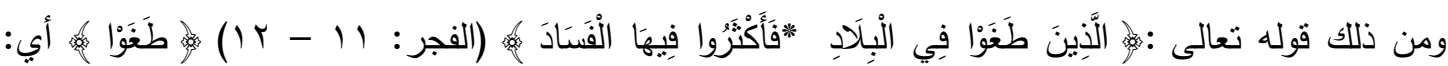

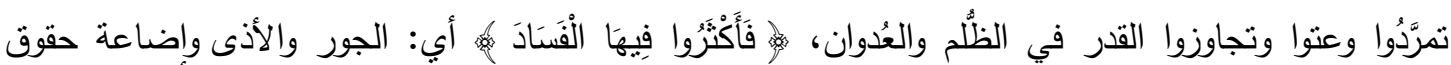

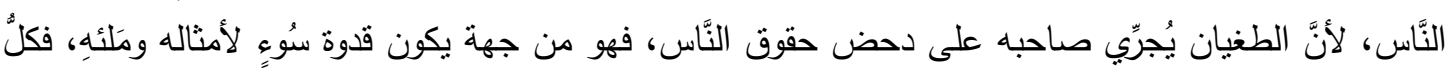

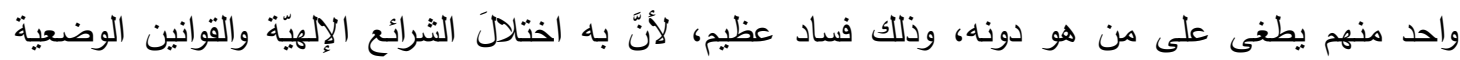

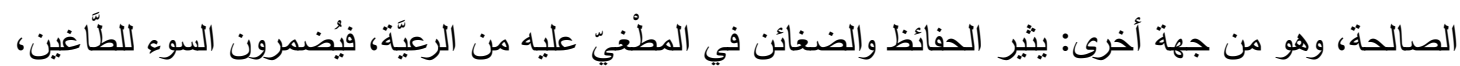

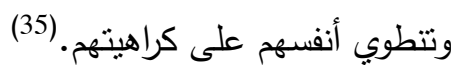

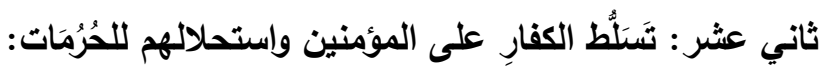

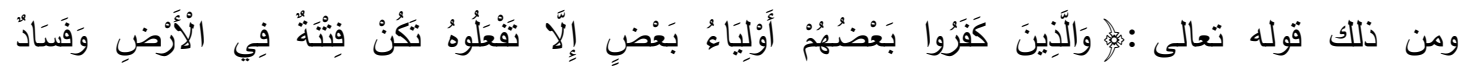

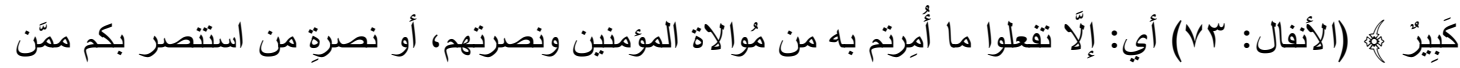

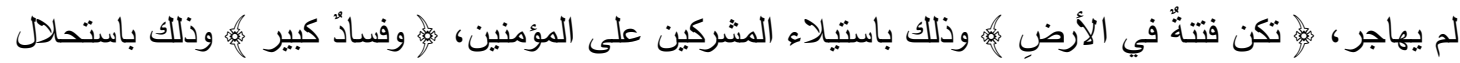

ثالث عشر : فساد نظام العالم:

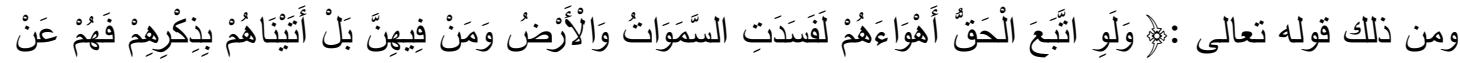

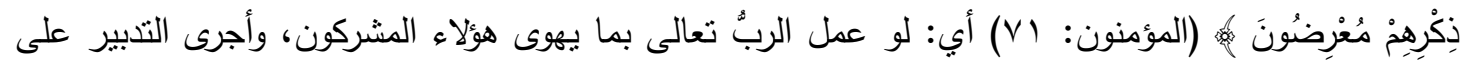

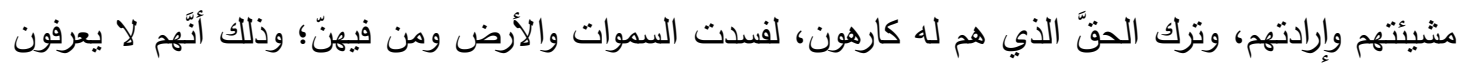
عواقب الأمور والصحيح من التدبير والفاسد، فلو كانت الأمور جارية على مشيئتهم وأهوائهم مع إيثار أكثرهم الباطل على الحقّ، لم تقرّ السموات والأرض ومن فيهنّ من خلق الله، لأن ذلك قام بالحق (37). 


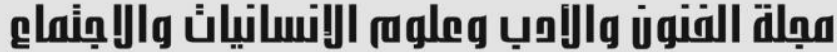

Journal of Arts, Literature, Humanities and Social Sciences www.jalhss.com

رابع عشر : النهي عن عموم الفساد:

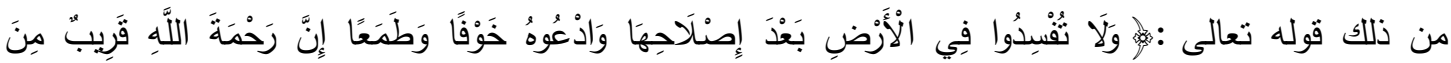



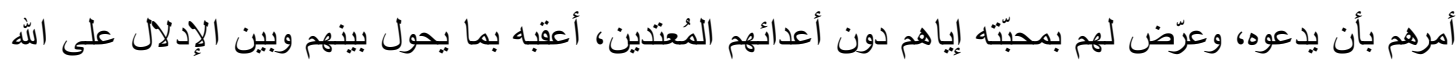

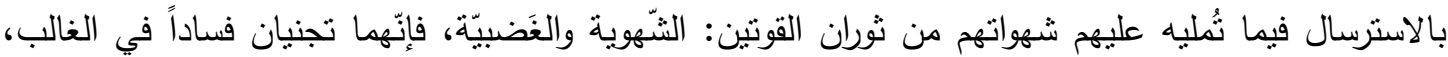

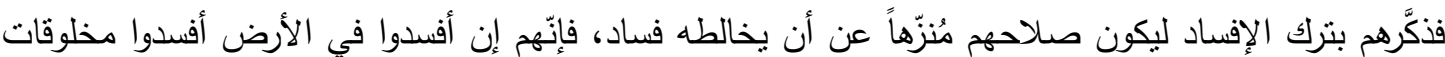

كثيرة، وأفسدوا أنفسهم في ضمن ذلك الإفسكن الإفساد (38). فالآية نهي عن إيقاع الفساد في الأرض وإخال ماهيته في الوجود، فيتعلق بجميع أنواعه: من إفساد النفوس

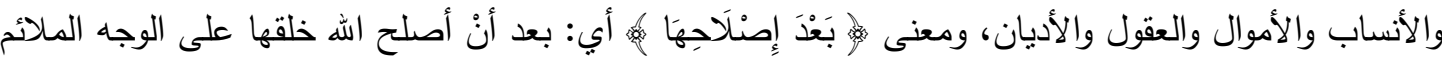
لمنافع الخلق ومصالح المكلَّفين (39).

\section{موقف الثريعة الإسلامية من الفساد والمفسدين}

لما كان الفساد نقيض الصلاح، والفساد يقع للنفس والبدن، ويوصف به كل ما هو خارج عن الاستقامة ، فإن من أعظم مقاصد الثريعة الإسلامية كما قرر علماء أصول الفقه : " جلب المنفعة ودرء المفسدة ، وقد ذهب العلماء إلى أبعد من ذلك حين قدموا درء المفسدة على جلب المنفعة، فإن تعارضت مصلحة ومفسدة وكان لا بد من ظهور المفسدة في طريق تحقيق المصلحة فإن الثنارع الحكيم يمنع السعي لتحقيق المصلحة تجنبا لوقوع المفسدة، وهذا ما دعا علماء الثريعة للقول بأن الثارع الحكيم اعتتى بالمنهيات أكثر من عنايته بالمأمورات ، وقد حارب القران الكريم الفساد وتوعد المفسدين بالخزي في الدنبا والعقاب في الاخرة.

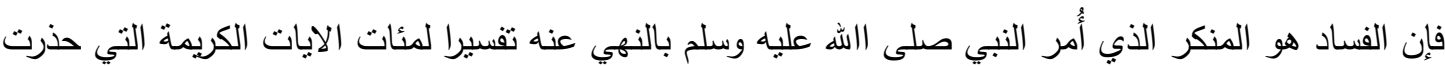

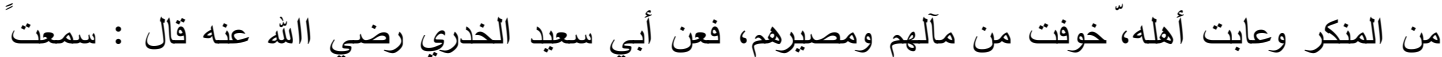

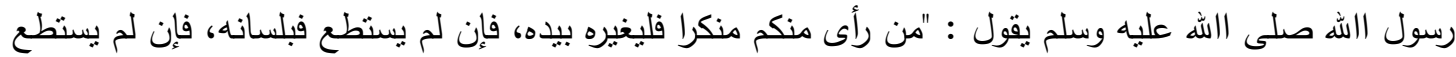

فبقلبه، وذلك أضعف الإيمان"، رواه مسلم. (40) هذا ولا تكاد تخلو سيرة المصطفى عليه والصلاة والسلام من كثير من الشواهد التي تظهر بشكل جلي وبما لا لا

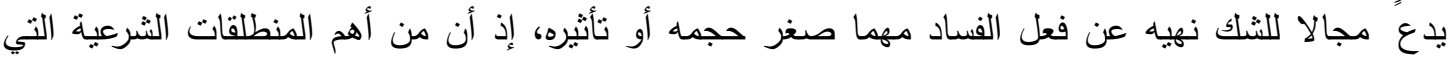

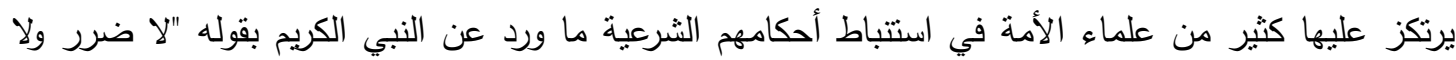
ضرار ." ضن

تصدي الثرع الحنيف لارء الفساد ومعالجته: ان الإسلام في شموله اهتم بظاهرة الفساد فثخص الداء ووصف الدواء، فلو عدنا إلى سورة الإسراء بمفردها لوجدنا الإبداع الرباني ينبه الناس إلى كل أثكال الفساد ويحث على تفاديه، فجاءت النصوص بهول بوحي منزلها

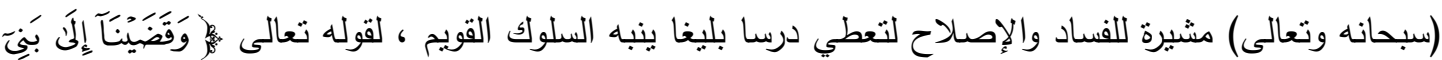

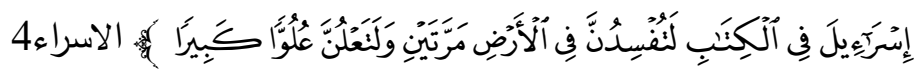




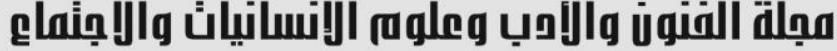

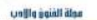

Journal of Arts, Literature, Humanities and Social Sciences www.jalhss.com

وقد جاء الإسلام، وفي أولوياته مكافحة الفساد وملاحقة المفسدين، فالله سبحانه وتعالى لا يحب الفساد ولا يصلح عمل المفسدين، والدار الآخرة هي من نصيب أولئك الذين قدموا أنفسهم كقرابين للصلاح ولمواجهة الفساد:

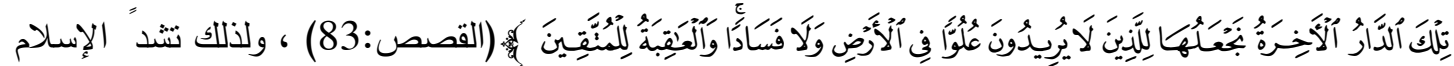

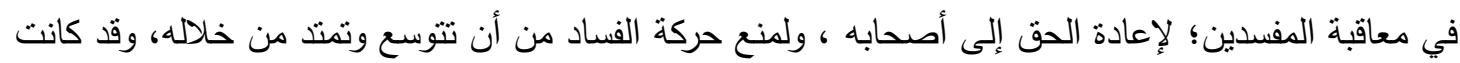

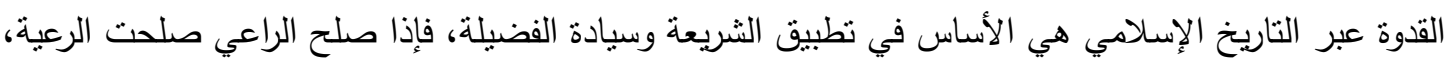

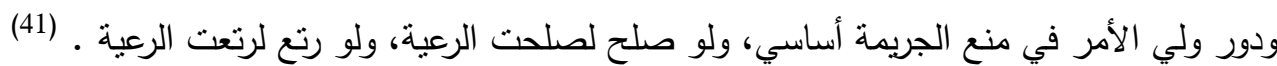

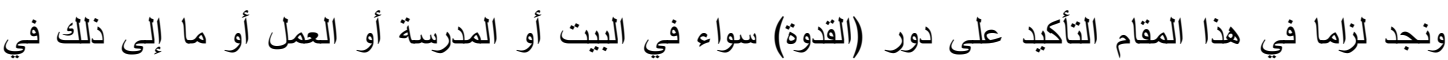
إصلاح الفرد والمجتمع، فالتنشئة الأسرية والتربية المدرسية يعتبران أول خطوات نقويم سلوك الفرد وخروجه إلى له العمل ليساهم في بناء المجتمع السوي والمنتج.

\section{الفساد في منظور السنة النبوية} مدلول مصطلح (الفساد) في السنة النبوية المطهرة السنة هي أحاديث رسول الله عليه السلام وأفعاله وتقريراته، وهي الأصل الثاني من أصول الدين، وتأتي أحاديث

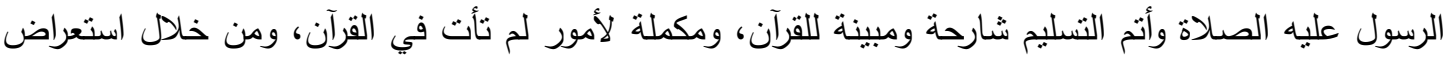

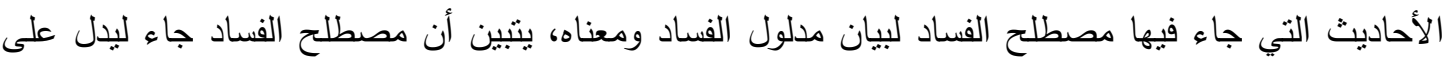
التي دل عليها القرآنً ويدل أيضا على : تلف الثيء وذهاب نفعه، وجاء من هذا قول الرسول عليه السلام : (الا وان في الجسد مضغة ، اذا صلحت صلح الجسد كله ، واذا فسدت فسد الجسد كله ، الا وهي القلب). (42) وأنى بمعنى تغير الحال إلى غير الصلاح، منل حديثه عليه السلام الذي برويه أبو هريرة رضي الله عنه قال: قال رسول الله عليه الصلاة والسلام: (المستمسك بسنتي عند فساد أمتي له أجر شهيد) ففساد الأمة هو تغيرها إلى غير صلاح. (43)

\section{بعض احاديث ذكرت في السنة النبوية عن الفساد} وكذلك فقد ورد في السنة النبوية المطهرة من الأحاديث ما يدل على وجوب مراعاة تذكر العرض على الله ليحاسب كل فرد عن أعماله وأقواله ومن هذه الأحاديث قوله عليه السلام "أيها الناس إن دمائكم وأموالكم عليكم

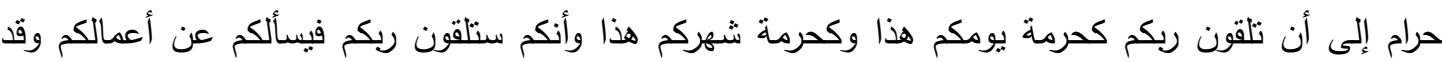
بلغت فمن كانت عنده أمانة فليؤدها إلى من ائتمنه"، وقوله عليه السلام "ما من عبد يسترعيه الله اله رعية يموت يوم يموت وهو غاش لرعيته إلا حرم الله عليه الجنة " . ومما سبق يتضح بأن الشعور الديني يعتبر خير وازع للإنسان لسلوك الطريق المستقيم وعدم ارتكاب المفاسد

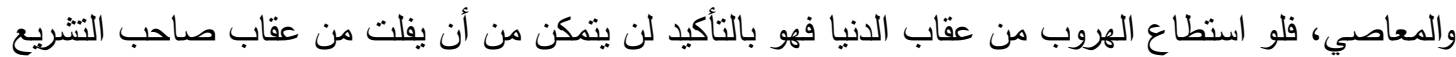




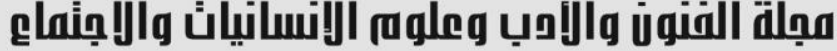

السماوي، إلا أن ذلك لم يمنع النفوس الضعيفة من مخالفة أوامر الله سبحانه وتعالى وارتكاب نواهيه، لذا كان

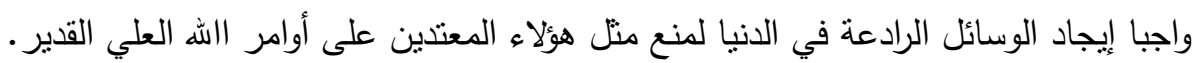

فالدين الإسلامي هو أكثر الأديان معرفة بنفسية البشر وكيفية معالجتها، ولذلك نجده قد استخدم أسلوبين لمعالجة ذلك الفساد، وهما أسلوب الترغيب والترهيب : ويقصد بأسلوب الترغيب: استخدام أساليب التحفيز المختلفة التي من شأنها أن تجعل الموظف يقبل على عملهً ، بنفس راضية وبحماس كبير فينجز إنجازا عاليا

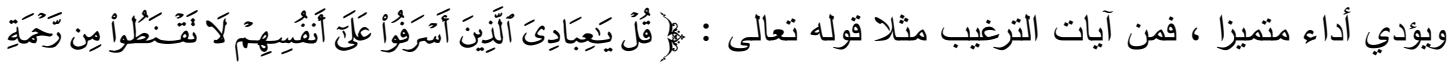

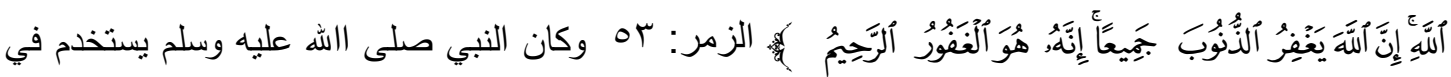

إدارته للاولة الإسلامية أسلوب الترغيب والترهيب ، فكان يحبب لهم عمل الخير وينهاهم عن فعل الثر . (44) أما أسلوب الترهيب : فيعتتي باستخدام أسلوب التخويف بأنواعه المتدرجة ويثار إليها في الإدارة الحديثة بالحافز

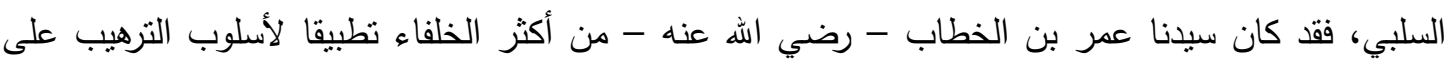

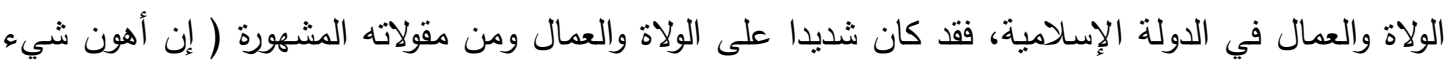

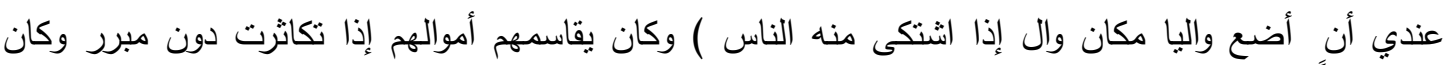
يعاقبهم إذا رأى فيهم الفساد أو الانحراف الإداري أو المالي. (45)

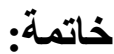

جاء الدين الإسلامي بمصادره التشريعية الأساسية (القرآن الكريم والسنة النبوية المطهرة) ومصادره الفرعية (كالقياس والاجتهاد) بنظرة شمولية لمكافحة الفساد بشتى أنواعه (سياسيا كان أم اقتصاديا ام اجتماعيا أم إدارياً )

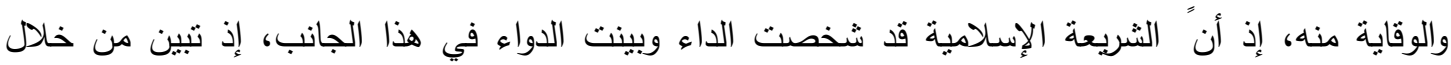
البحث أن كلمة (فسد) ، ومشتقاتها قد وردت في القران الكريم في (خمسين) موضعا ، ناهيك عن الأحاديث النبوية الثريفة وسيرة النبي صلى الله عليه وسلم والخلفاء الراثدين التي تتاولت التحذير من هذه الآفة الهدامة

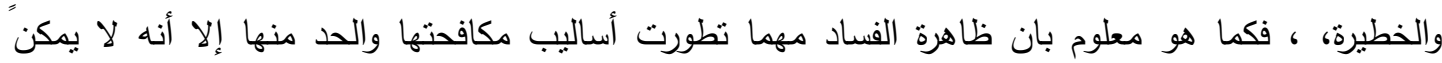

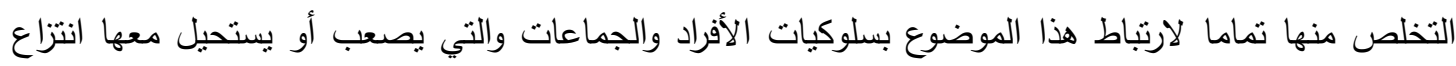

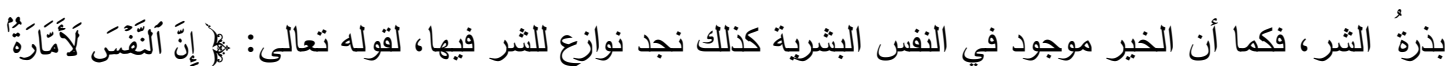

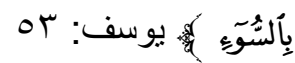
إلا أنه وعلى الرغم من ذلك فقد جاء الدين الإسلامي بقواعد وأحكام هدفت إلى الحد من هذه الظاهرة ما أمكن،

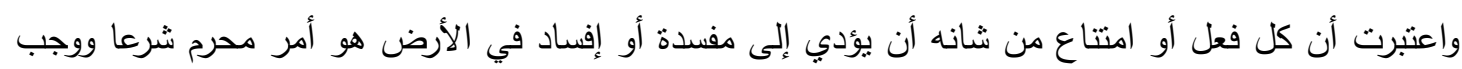

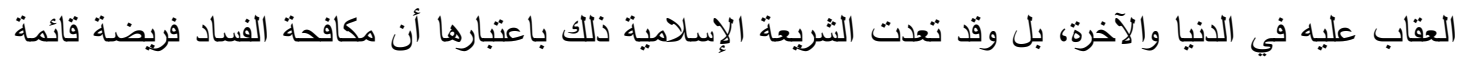

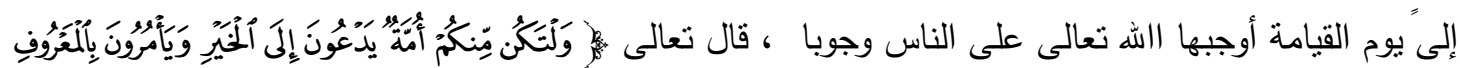

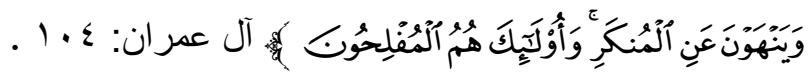




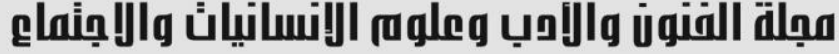

Journal of Arts, Literature, Humanities and Social Sciences www.jalhss.com

وأصبحت ظاهرة الفساد ظاهرة عالمية و سرطانا يستشري في جسم الدول نتيجة فقدان الهنمع لقبمه و منله و لعدم تكريس القانون و فرض احترامه على الجميع و عدم نشر مفهوم المواطنة و غياب ثقافة حقوق الإنسان ، و نتيجة لهذا بستحيل أن يكون الهجتمع الفاسد قويا و عادلا و متحضرا و يسرد التاريخ أن هناك إمبراطوريات

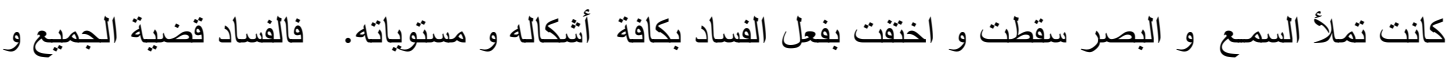
مكافحته نشاط يعني الجميع أيضا و هو بهذا المعنى واجب شرعي و وطني و أخلاقي فقد أقرت مؤسسات دولية

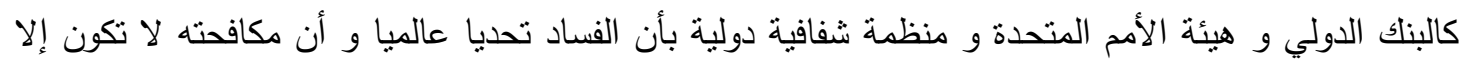

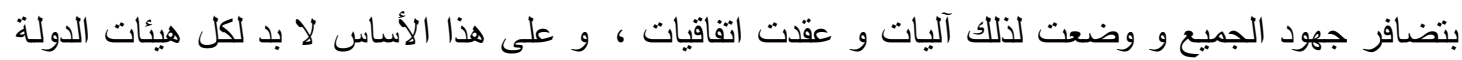

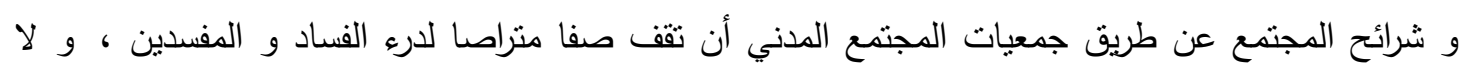

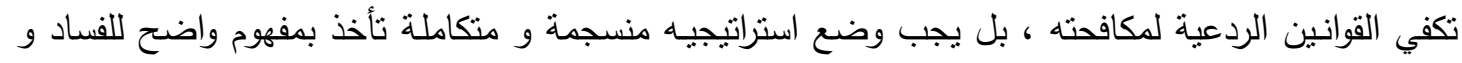
تحديد عوامله و أسبابه و التركيز على نشر القيم و المنل العليا و تفعيل دور الدولة في حفظ حق المواطن في الكرامة و العيش الرغيد بما يحفظه و يجعله مواطنا صالحا في شتى مراتب المسؤولية .

التوصيات

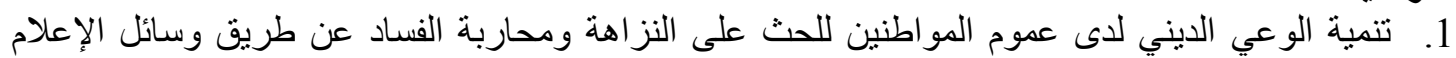

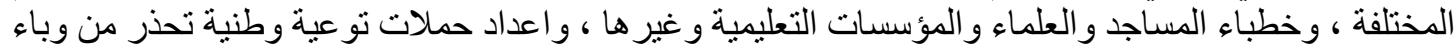

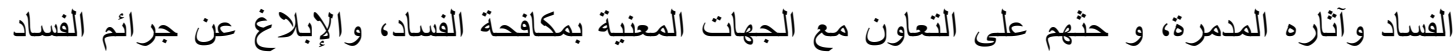
ور مرتكبيها .

2. التأكيد على دور الأسرة في تربية والنشئة ودور ها الأساسي في بناء مجتمع مسلم مناهض لأفعال الفساد .

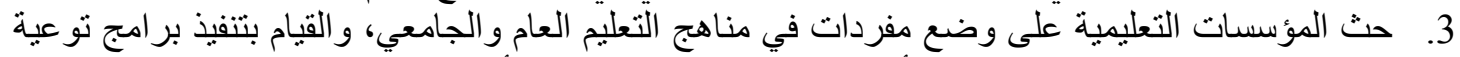

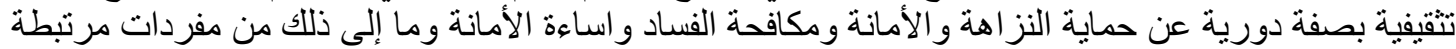

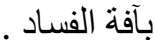
4. تفعيل أدوار الجهات المعنية بمكافحة الفساد، ومنحها الاستقالالية الكاملة في ممارسة أعمالها، و التأكيد عليها

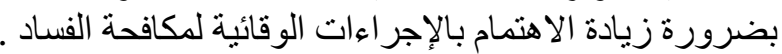

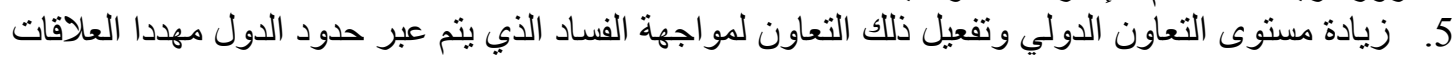
الاقتصادية و السياسية بين الثعوب النعار و الحكومات .

\section{الهوامش}

(1)تقرير الامم المتحدة ، مكافحة الفساد: اطر دستورية لمنطقة الثرق الاوسط وشمال افريقيا ، ص 10

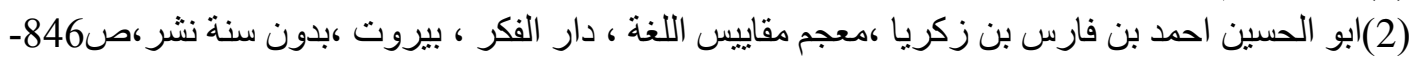




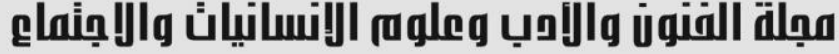

Journal of Arts, Literature, Humanities and Social Sciences www.jalhss.com

(1) (رفيق يونس، أصول الاقتصاد الإسلامي، دمشق: دار القلم، صفحة 12.

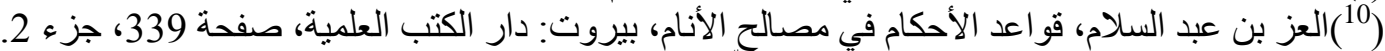

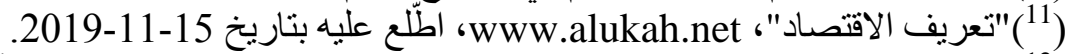
(22)حسن عبد الرازق منصور (2013)، بناء الإنسأن (الطبعة الثنانية )، عمان- الأدرن: أمواج للنشر والتوزيع، صفحة 187. (13 ("تعريف و معنى مجتمع في معجم المعاني الجامع"، www.almaany.com، اطلّع عليه بناريخ 2018-3-

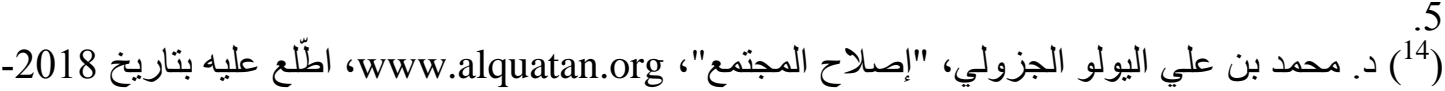
$\left({ }^{15}\right)$ Adam Graycar (3-3-2017), "Corruption: Classification and analysis" ، www.tandfonline.com, Retrieved 30-8-2018. Edited.

$$
\begin{aligned}
& \text { (16) سورة البقرة: • بـ }
\end{aligned}
$$

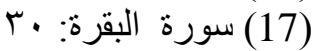

$$
\begin{aligned}
& \text { (18) سورة الإنسان: باهن }
\end{aligned}
$$

(19) يماني، هناء، الفساد الإداري وعلاجه من منظور إسلامي، (http//www.saaid.net/Book,7,) 1291.doc)

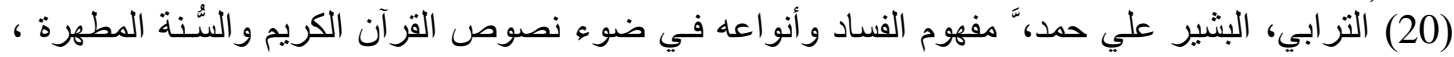

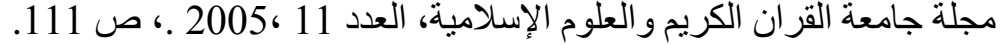

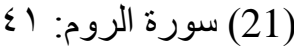
(22) الو ائلي، ياسر خالد، الفساد الإداري، مفهومه وأسبابه، مع الإشارة إلى تجربة العر اق في الفساد، مجلة النبأ،

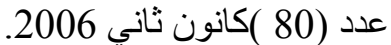

(23) انظر : تفسير ابن عطية 1: 99، 200، تفسير القرطبي 1: 247، تفسير البيضاوي 1: 267، تفسير أبي حيان 1:

(24) انظر : الجامع لأحكام القرآن 7: 248: 248، البحر المحيط لأبي حيان 4: 340، البحر المديد 2: 515.

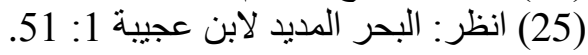

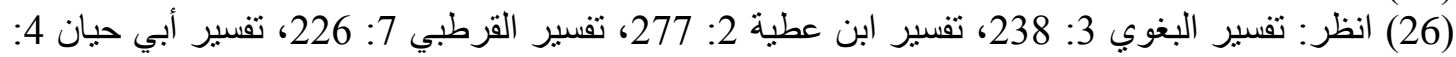
313، تفسير ابن عجيبة 2: 2 2: 499.

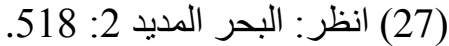
(28) انظر: المحرر الوجيز 4: 95، 18 الجامع لأحكام القرآن 11: 279، البحر المديد 4: 499، روح المعاني 17:

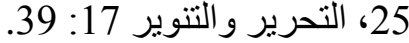

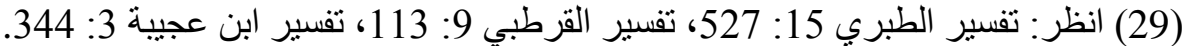

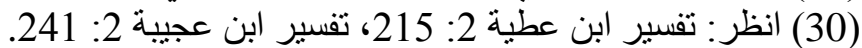

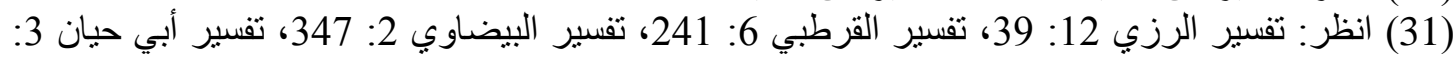

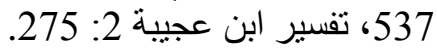

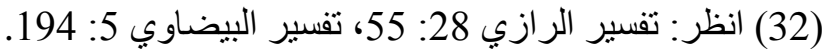

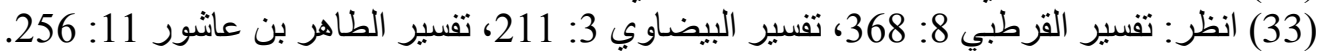
(34) انظر: تفسير الطبري 4: 356، 357، تفسير الزمخشري 1: 291: 291، تفسير القرطبي 3: 66، تفسير البيضاوي 1: .506

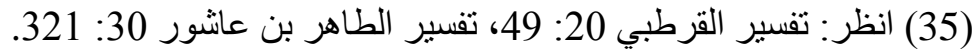

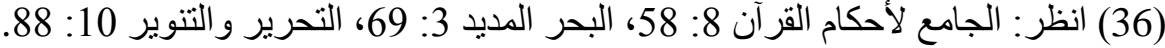

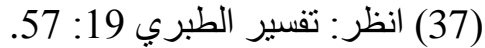

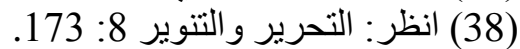
(39) انظر: البحر المحيط لأبي حيان 4: 1313 (313. 


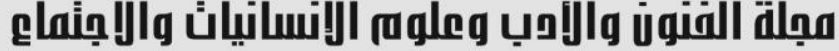

Journal of Arts, Literature, Humanities and Social Sciences www.jalhss.com

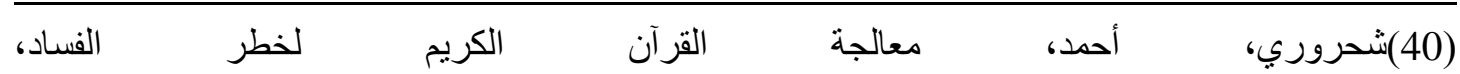

.(http//www./localhost/mohafatha/details.php?id=492)

(41) عبد الباقي، علي، المنهج الإسلامي في مواجهة الفساد والمفسدين ، منشورات موقع لواء الثريعة،

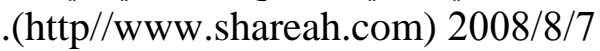

(42) الثيخان، البخاري ومسلم، البخاري في كتاب الإيمان برقم (50/30 ،(ومسلم في كتاب المساقاة برقم (2996.

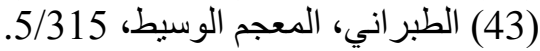

(44) بحر، يوسف، ـ الفساد الإداري ومعـالجته من منظور إسلامي، ص 25 (4ttp// www.scc- ). online.net)

(45) الثلعوط، فريز محمود احمد، نظريات في الإدارة التربوية ، مكتبة الرشد، الرياض، السعودية، 2002 ،

1. ابن عطية ، أبو محمد عبد الحق بن غالب بن عبد الرحمن بن تمام ، المحرر الوجيز في تفسير الكتاب العزيز

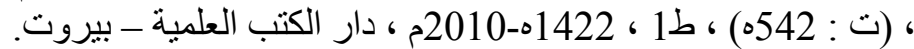

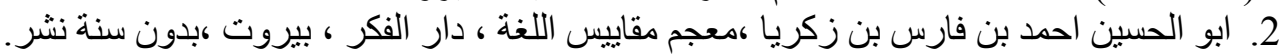

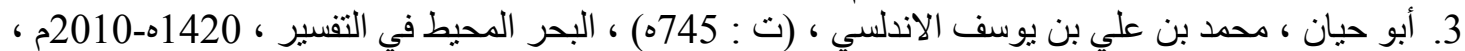

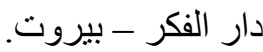

4. بحر، يوسف، - الفساد الإداري ومعـالجته من منظور إسلامي، ص 25 (http// www.scc- ). online.net) 5. البغوي ، أبو محمد الحسين بن مسعود ، (ت : 510ه) ، معالم التنزيل في تفسير القران ، ط4 ، 1417هـ

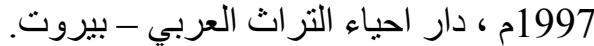
6. البيضاوي ، ناصر الدين أبو سعيد عبداله بن عمر ، (ت : 685ه) ، ط1 ، 1418ه 2010م ، دار احياء التراث

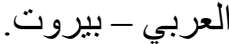

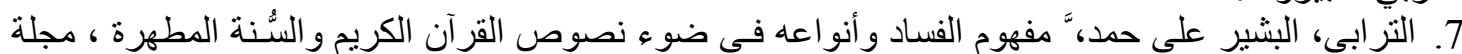

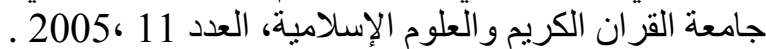

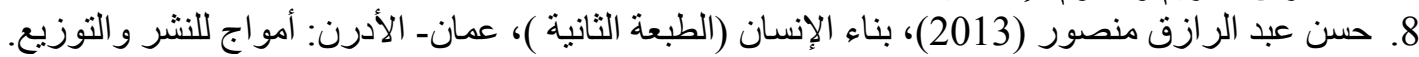

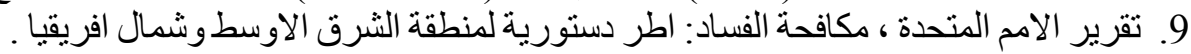

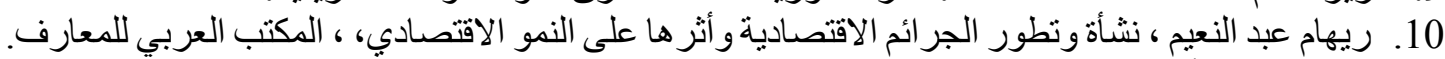

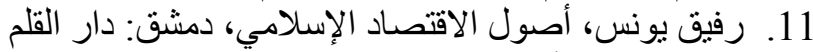

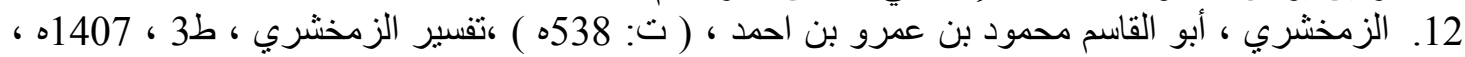
13. شحروري، الكتاب العربي - بيروت. .http//www./localhost/mohafatha/details.php?id=492)

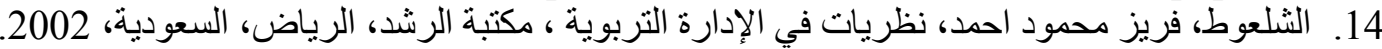

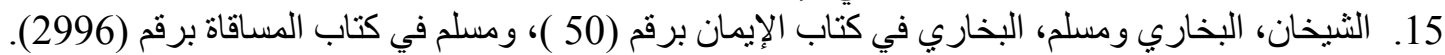

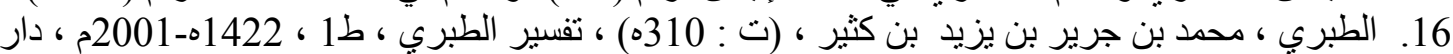
هجر للطباعةٌ والنشر و التوزيع. 17. عبد الباقي، علي، المنهج الإسلامي في مواجهة الفساد والمفسدين ، منشورات موقع لواء الثريعة، .http//www.shareah.com) 2008/8/7 


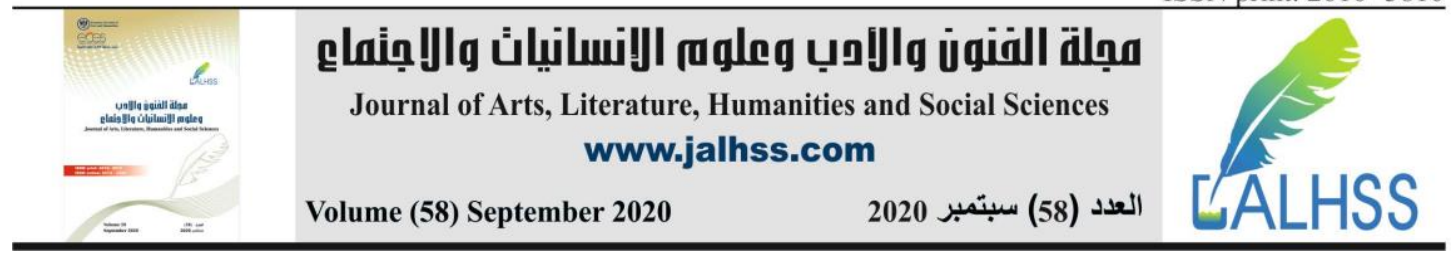

18. القرطبي ، أبو عبداله محمد بن احمد الانصاري ، (ت : 671ه) ، الجامع لاحكام القران ، ط2 ، 1384هـ

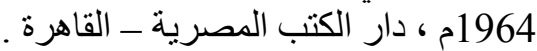

19. الوائلي، ياسر خالّا، الفساد الإداري، مفهومه و أسبابه، مع الإشارة إلى تجربة العر اق في الفساد، مجلة النبأ،

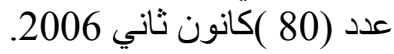

20. يماني، هناء، الفساد الإداري وعلاجه من منظور إسلامي، (http//www.saaid.net/Book,7). 1291.doc)

\section{References}

1. Ibn Attiyah, Abu Muhammad Abd al-Haq bin Ghaleb bin Abd al-Rahman bin Tamam, the brief editor in the interpretation of the Aziz Book, (T: $542 \mathrm{AH})$, 1st Edition, 1422 AH-2010 AD, Dar Al-Kutub Al-Ilmiyya - Beirut.

2. Abu Al-Hussein Ahmad Bin Faris Bin Zakaria, Dictionary of Language Standards, Dar Al-Fikr, Beirut, without a year of publication.

3. Abu Hayyan, Muhammad bin Ali bin Yusef al-Andalusi, (d .: 745 AH), The Ocean in Tafsir, 1420 AH-2010 CE, Dar Al-Fikr - Beirut.

4. Bahr, Yusef, - Administrative corruption and its treatment from an Islamic perspective, p. 25 (http://www.scc-online.net)

5. Al-Baghawi, Abu Muhammad Al-Hussein Bin Masoud, (d .: 510 AH), Landmarks of revelation in the interpretation of the Qur'an, ed. 4, 1417 AH -1997 AD, House of Revival of Arab Heritage - Beirut.

6. Al-Baidawi, Nasir Al-Din Abu Saeed Abdullah Bin Omar, (T .: 685 AH), 1st Edition, 1418 AH-2010 AD, House of Revival of Arab Heritage - Beirut.

7. Al-Turabi, Al-Bashir Ali Hamad, The Concept of Corruption and its Types in Light of the Texts of the Holy Qur'an and the Sunnah, Journal of the University of the Holy Quran and Islamic Sciences, Issue 11, 2005.

8. Hassan Abd Al-Raziq Mansour (2013), Building the Human (second edition), Amman - Jordan: Amwaj for Publishing and Distribution.

9. The United Nations Report, Anti-Corruption: Constitutional Frameworks for the Middle East and North Africa.

10. Reham Abdel-Naim, The Origins and Development of Economic Crimes and Their Impact on Economic Growth, The Arab Bureau of Knowledge.

11. Rafiq Yunus, The Origins of Islamic Economy, Damascus: Dar Al-Qalam

12. Al-Zamakhshari, Abu al-Qasim Mahmoud bin Amr bin Ahmed, (T .: 538 AH), Tafsir al-Zamakhshari, ed 3, 1407 AH, Arab Book House - Beirut.

13. Shahrouri, Ahmad, The Holy Quran's Treatment of the Danger of Corruption, (http://www. / Localhost / mohafatha / details.php? Id = 492).

14. Al-Shalout, Fariz Mahmoud Ahmad, Theories in Educational Administration, AlRashed Library, Riyadh, Saudi Arabia, 2002.

15. The two Sheikhs, Al-Bukhari and Muslim, Al-Bukhari in the Book of Faith No. (50), and Muslim in the Book of Al-Masqah No. (2996).

16. Al-Tabari, Muhammad bin Jarir bin Yazid bin Kathir, (d .: $310 \mathrm{AH})$, Tafseer alTabari, ed. 1, 1422 AH -2001 AD, Dar Hajar for printing, publishing and distribution. 


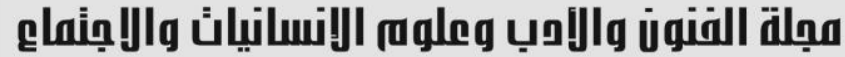 \\ Journal of Arts, Literature, Humanities and Social Sciences www.jalhss.com}

Volume (58) September 2020

العدد (58) سبتمبر 2020 (20)

17. Abdul-Baqi, Ali, The Islamic Approach to Confronting Corruption and Corrupt, Publications of the Sharia Brigade website, 7/8/2008. (Http://www.shareah.com)

18. Al-Qurtubi, Abu Abdullah Muhammad Ibn Ahmad Al-Ansari, (d .: 671 AH), AlJami 'to the Rulings of the Qur'an, 2nd Edition, 1384 AH-1964 AD, the Egyptian House of Books - Cairo.

19. Al-Waili, Yasser Khaled, Administrative Corruption, Its Concept and its Causes, with reference to Iraq's experience in corruption, Al-Nabaa Magazine, Issue (80) January 2006.

20. Yamani, Hana, Administrative Corruption and Its Treatment from an Islamic Perspective, (http://www.saaid.net / Book, 7, 1291.doc). 